\title{
Persistent, symptomless, systemic, and seed-borne infection of lettuce by Botrytis cinerea
}

Article

Accepted Version

Sowley, E. N. K., Dewey, F. M. and Shaw, M. W. (2010) Persistent, symptomless, systemic, and seed-borne infection of lettuce by Botrytis cinerea. European Journal of Plant Pathology, 126 (1). pp. 61-71. ISSN 0929-1873 doi: https://doi.org/10.1007/s10658-009-9524-1 Available at https://centaur.reading.ac.uk/16489/

It is advisable to refer to the publisher's version if you intend to cite from the work. See Guidance on citing.

To link to this article DOI: http://dx.doi.org/10.1007/s10658-009-9524-1

Publisher: Springer

Publisher statement: The original publication is available at www.springerlink.com

All outputs in CentAUR are protected by Intellectual Property Rights law, including copyright law. Copyright and IPR is retained by the creators or other copyright holders. Terms and conditions for use of this material are defined in the End User Agreement.

www.reading.ac.uk/centaur

\section{CentAUR}


Central Archive at the University of Reading

Reading's research outputs online 


\section{PERSISTENT, SYMPTOMLESS, SYSTEMIC, AND SEEDBORNE INFECTION OF}

\section{LETTUCE BY BOTRYTIS CINEREA}

E. N. K. Sowley ${ }^{1,2}$, F.M. Dewey ${ }^{3}$ and M. W. Shaw ${ }^{1 *}$

${ }^{1}$ School of Biological Sciences, University of Reading, Whiteknights, Reading, RG6 6AS, UK; Email: m.w.shaw@ reading.ac.uk FAX +44-118 3788032

${ }^{2}$ Department of Agronomy, University for Development Studies, P. O. Box TL 1882, Tamale, Ghana : Email enksus@yahoo.com

${ }^{3}$ School of Plant Sciences, University of Oxford, South Parks Road, Oxford OX1 3RB, UK; Email: f.m.dewey@plantsci.ox.ac.uk

*To whom correspondence should be addressed

This is the authors' final manuscript. The definitive type-set and copy-edited version of the article can be obtained from the publisher's website (DOI: 10.1007/s10658-009-9524-1) or the printed version of the journal. 


\section{SUMMARY}

Experiments are presented which show that Botrytis cinerea, the cause of gray mould disease, is often present in symptomless lettuce plants as a systemic, endophytic, infection which may arise from seed. The fungus was isolated on selective media from surface sterilized sections of roots, stem pieces and leaf discs from symptomless plants grown in a conventional glasshouse and in a spore-free air-flow provided by an isolation propagator. The presence of $B$. cinerea was confirmed by immuno-labelling the tissues with the Botrytis-specific monoclonal antibody BC-12.CA4. As plants grew, infection spread from the roots to stems and leaves. Surface sterilization of seeds reduced the number of infected symptomless plants. Artificial infection of seedlings with dry conidia increased the rate of infection in some experiments. Selected isolates were genetically finger-printed using microsatellite loci. This confirmed systemic spread of the inoculating isolates but showed that other isolates were also present and that single plants hosted multiple isolates. This shows that B. cinerea commonly grows in lettuce plants as an endophyte, as has already been shown for Primula. If true for other hosts, the endophytic phase may be as important a component of the species population as the aggressive necrotrophic phase.

Keywords: Botryotinia fuckeliana, endophyte, gray mould, Lactuca sativa, latent, vertical disease transmission 


\section{INTRODUCTION}

Endophytic infection of higher plants by a range of fungi is recognised as extremely common and functionally important. Many fungi are involved, which may exist as saprotrophs (eg Acremonium strictum (Jallow et al., 2008)), be vertically transmitted via seed (eg the Neotyphodium endophytes of grasses (Lemons et al., 2005), or reproduce via production of propagules at distinct phases of the host life-cycle (eg choke disease, (Tintjer et al., 2008). Endophytes have been shown to affect insect damage both directly and indirectly (Hartley \& Gange, 2009), to alter susceptibility of plants to infections caused by other fungi and viruses, and to alter mycorrhizal status (Omacini et al., 2006).

By contrast, Botrytis cinerea (teleomorph Botryotinia fuckeliana) is regarded as a model necrotrophic organism (Williamson et al., 2007), and causes considerable problems in many sectors of temperate horticulture (Elad et al., 2004). It is usually considered to multiply through conidia which infect directly to cause spreading necrotrophic lesions, and much is known about the signals and biochemistry involved. In grape, kiwi, strawberry and other hosts, it may infect to form a small infection which then becomes quiescent and is activated by the onset of senescence or stress of the host tissue (Bristow et al., 1986; Coertze \& Holz, 2002; Keller et al., 2003; Michailides \& Elmer).

However, Barnes \& Shaw (2003) found that B. cinerea could grow systemically but without symptoms in cultivated Primula x polyantha, so that a single isolate could be present throughout an apparently healthy plant - an endophytic infection. These infections arose from airborne spores but appeared also to be seedborne, commonly externally but sometimes also within seed.

Systemic infection by $B$. cinerea has been reported only in Primula $x$ polyantha, but is known from several related pathogens. The first report appears to be that of Silow (1933) working on B. anthophila in Trifolium pratense, but this has not been followed up. Silow showed that spores of B. anthophila were disseminated by bees and germinate with pollen grains on the stigmas of healthy red clover plants, leading to the development of an intraseminal mycelium from which a systemic infection of the adult plant was derived.

Seed infection by $B$. cinerea leading to disease is known in several species, including for example linseed (Linum usitatissimum) (Harold et al., 1997), chickpea (Cicer arietinum) (Burgess et al., 1997) and lentil (Huang \& Erickson, 2005). In most cases it is reported because the infection causes seedling mortality and the dead seedlings provide a source of inoculum for the surviving crop. Burgess et al. (1997) showed that infection of chickpea seeds did not result in systemic infection.

McNeill (1953) reported isolating a distinct root infecting form of $B$. cinerea from lettuce root; the distinction lay in its abundance in the roots of plants with unaffected leaves rather than in any morphological distinction. Although McNeill's isolates were very aggressive, the natural etiology was not clarified and, in view of the results from Primula, it was thought worthwhile to study whether lettuce could harbour systemic $B$. cinerea infection. In preliminary studies, $B$. cinerea was frequently isolated from some batches of lettuce seed both before and after surface sterilisation. The aims of the present study were therefore to investigate whether systemic infection of lettuce by Botrytis cinerea occurred and whether seed infection could lead to infection of the seedlings. 


\section{MATERIALS AND METHODS}

\section{Culture of Botrytis cinerea and isolation of the fungus from plant tissues}

B. cinerea isolates, B2 (isolated from Primula $x$ polyantha at Reading), ES23 and ES27 (both isolated from lettuce at Reading in 2004) were maintained on 3\% Malt Extract Agar (MEA, CM0059, Oxoid, Basingstoke), and sporulation encouraged by exposure to continuous near UV light once cultures had covered a plate. Botrytis Selective Medium (BSM) was used for detection and isolation of the fungus from plant tissues (Edwards \& Seddon, 2001).

\section{Seed stocks}

Seeds of the following four commercially available cultivars were used: All The Year Round, Little Gem, Tom Thumb [Unwin's Seeds Ltd, Cambridge, UK] and Webbs Wonderful [Johnsons Seeds, Newmarket Suffolk, UK]). Harvest year was 2003 for the 2004 experiments and 2004 for the 2005 experiments. These were stored dry at $4{ }^{\circ} \mathrm{C}$ until sown ("stored seed"). For the seed to seedling transmission work, a further two stocks were used which had high seed infection rates. These were (1) seed of cv. Little Gem grown in a garden near Reading and harvested in autumn 2003 and (2) seed of $\mathrm{cv}$. Tom Thumb, inoculated at the two-leaf stage with dry spores of B. cinerea isolate ES27, grown in the University of Reading Experimental grounds and harvested in autumn 2005 ("field seed"). The remaining Tom Thumb seed not sown in spring 2005 was stored dry at $4{ }^{\circ} \mathrm{C}$ ("stored seed").

\section{Plant growth and soil sterilisation}

Unless otherwise stated seeds were sown in plug trays of non-sterilised soil-based compost (John Innes 1) in a glasshouse illuminated with natural light. For two experiments seedlings were grown in a sterile air flow in an isolation propagator (Burkhard manufacturing, Hemel Hempstead, UK) and for one these experiments, the soil was sterilised by three cycles of dry heating at $80^{\circ} \mathrm{C}$ for $2 \mathrm{~h}$ followed by $22 \mathrm{~h}$ at room temperature.

\section{Isolation of $B$. cinerea from plant tissues and seed}

One $\mathrm{cm}$ long sections of secondary roots, $1 \mathrm{~cm}$ diameter discs of leaves and hand cut $1 \mathrm{~mm}$ sections of stems were surface sterilised by the same method used to sterilise seeds. All the sections were plated out on BSM and observed at intervals for up to three weeks. Seeds were surface sterilised by rinsing in running water, immersion in 50\% commercial bleach (Domestos, Unilever: $5 \% \mathrm{NaOCl}$ in alkaline solution plus surfactants) for 3 minutes, followed by two rinses in sterile water. This was shown by Barnes (2002) to remove all artificially applied surface inoculum, whether dusted or soaked in and allowed to dry. Seeds were plated out on MEA plates to check for efficacy of sterilisation and observed at intervals for up to three weeks. Suspected B. cinerea colonies which did not sporulate were checked by transfer to MEA. 


\section{Artificial infection of seedlings}

To inoculate plants, seedlings were moved from the glasshouse to an enclosed laboratory about $30 \mathrm{~m}$ away and placed at the base of a settling tower. A single 14-day old sporulating culture of $B$. cinerea on MEA was inverted at the top of the settling tower and tapped gently to detach spores. The seedlings were left for half an hour to allow spores to settle and then transferred into black polyethylene bags and stored in the dark (to avoid overheating and excessive condensation) for 24 hours at approximately $20{ }^{\circ} \mathrm{C}$ before removing the covering bags and returning them to the glasshouse.

\section{Immunofluorescence labeling and microscopy}

Hand cut sections of stems, ca. $0.5 \mathrm{~mm}$ thick at maximum, secondary roots and leaf discs from plants were placed on glass slides and squashed gently. A water tight border was made around them using vaseline extruded from a syringe. All incubations were done in closed Petri dishes. The specimens were incubated sequentially with $100 \mu \mathrm{l}$ of $30 \mathrm{~g} / \mathrm{L}$ of paraformaldehyde in PBST for 30 minutes, blocking buffer ( $3 \mathrm{~g} / \mathrm{L}$ casein in PBST) for 30 minutes, undiluted hybridoma supernatant BC-12.CA4 (Meyer \& Dewey, 2000) for 2 hours, anti-Mouse IgG Texas Red (Calbiochem, UK, catalogue DC18L) diluted 1 in 40 in PBST for 2 hours. All incubations were done at room temperature and between each incubation step the specimens were washed 3 times with PBST for 2 min each time. After a final washing step and removal of the PBST the specimens were mounted in Citifluor (Citifluor Ltd, London). Slides were wrapped in foil and stored at $4^{\circ} \mathrm{C}$ before examination with a Leica TCS SP2 AOBS confocal laser scanning microscope mounted on a Leica inverted DM IRE2 microscope (Leica Microsystems GmbH, Heidelberg), using the manufacturer's image capture software (TCS SP2 AOBS). Samples were excited at $589 \mathrm{~nm}$ with a He-Ne laser, and emissions collected between 606 $661 \mathrm{~nm}$, using a $\times 20$ glycerol objective.

\section{Genotype fingerprinting of $B$. cinerea isolates}

Mycelium of the isolates were grown, separately, in shake cultures in Malt Yeast Broth (MYB, yeast extract, $3 \mathrm{gL}^{-1}$; malt extract, $3 \mathrm{gL}^{-1}$; peptone, $5 \mathrm{gL}^{-1}$; and dextrose, $10 \mathrm{gL}^{-1}$ all from Oxoid, Basingstoke, UK) for 7 days. Harvested mycelium was rinsed in sterile nanopure water and ground to a fine powder in liquid nitrogen using a pestle and mortar. DNA was extracted using DNeasy Plant Mini Kits (Qiagen, West Sussex, UK), stored at $-20^{\circ} \mathrm{C}$ and adjusted to $10 \mathrm{ng} / \mu \mathrm{l}$ using a Pico-Green assay (Invitrogen, UK).

DNA extracts of the $B$. cinerea isolates were characterised using nine microsatellite primers as published by Fournier et al. (2002) labelled with FAM (Blue), HEX (Green) or NED (Yellow). Each reaction contained $5 \mu \mathrm{l}$ Biomix (Bioline, UK), $2 \mu \mathrm{l}$ water, $1 \mu \mathrm{l}$ each of forward and reverse primers and $1 \mu \mathrm{l}$ template DNA. Each amplification was run once. Three amplification reactions using complementary dye markers were mixed for fragment analysis in an ABI Prism 3130xl Genetic Analyser (Applied Biosystems, USA). Primers Bc1, Bc2, Bc3, Bc5, Bc6 and Bc9 were run with an initial denaturing step of $2 \mathrm{~min}$ at $94{ }^{\circ} \mathrm{C}$, followed by 35 cycles of $1 \mathrm{~min}$ at $94{ }^{\circ} \mathrm{C}, 1 \mathrm{~min}$ annealing at 53 ${ }^{\circ} \mathrm{C}, 30$ secs at $72{ }^{\circ} \mathrm{C}$ and $5 \mathrm{~min}$ at $72{ }^{\circ} \mathrm{C}$. Primers Bc4, Bc7 and $\mathrm{Bc} 10$ had an annealing temperature of 
$59{ }^{\circ} \mathrm{C}$ instead. Amplicon lengths were scored manually from the electrophoregraphs. B. cinerea ES23 was used as standard in each batch of amplifications.

\section{Experimental design}

2004- Glasshouse. Prior to sowing, 50 sterilised and 50 non-sterilised seeds of each variety were plated on BSM to determine the initial level of infection. All four varieties were sown in seedling plug trays, one variety in each quarter of each tray, on 23 Oct 2003. This experiment used a factorial design with the main factors a) variety b) seed sterilization and c) inoculation. Seedlings were dry-inoculated at the two-leaf stage, 7 days after sowing, with spores of isolate B2. The density of deposition was not measured but the technique was the same as in 2005. Seedlings were then transplanted to $10 \mathrm{~cm}$ round pots and arranged in randomised blocks in a single glasshouse. When the seedlings were two months old 8 inoculated and 8 control seedlings per variety were sampled, dissected and plated on BSM.

2005-Glasshouse This experiment used a similar design to the 2004 glasshouse experiment, but with 18 plants per treatment and three successive harvests. Seed were sown on 6 Jan 2005 . At one month after planting (MAP), at the 6-leaf stage, 2 trays of seedlings from sterilised seed and 2 trays from nonsterilised seeds were sampled, as in the 2004 glasshouse experiment. The remaining seedlings were dry inoculated with spores of B. cinerea ES27. Approximately $12 \pm 5$ spores $/ \mathrm{mm}^{2}$ were deposited, based on microscopic examination of acetate sheets placed in each tray. Cultures of ES27 produced spreading brown necrotic lesions when drop inoculated at 5000 spores/drop on detached lettuce leaves. Subsequent samples of the crop were taken at 2.5 and 3.5 MAP. At 2.5 MAP 27 isolates were genotyped, one each from root, stem and leaf of nine plants from which isolates were recovered from all tissues.

\section{Transmission of seed infection to seedlings}

To test whether $B$. cinerea was transmitted from seed to seedlings, infected seeds were grown in a spore-free airflow created within an isolation propagator (Burkhard Manufacturing Co, Rickmansworth, Hertfordshire, UK). To avoid excessive shading, only the top two of the four trays in the propagator were used but light levels were low due to the acrylic pot-covers forming part of the isolation system, and shading of the glasshouse by surrounding trees.

The 2005 and 2006 propagator experiments used a $2^{2}$ factorial design with trays in the propagator as blocks each containing 7 replicates randomly arranged. Experimental factors in the 2005 propagator experiment were soil sterilisation (+/-) and seed surface sterilisations (+/-). Each pot was sown with 6 seed of cv. Little Gem, from a crop grown at Reading in 2003, with a germination rate of about $40 \%$. A single plant was harvested from each pot. In the 2006 propagator experiment experimental factors were seed surface sterilisation (+/-) and seed source (+/-). Two types of seed were used. The first type was commercial seed of cv. Tom Thumb, stored at $4{ }^{\circ} \mathrm{C}$ since 2005 (stored seed). The second type was the offspring of the first type, harvested from plants grown outdoors during 2005, as above (field seed). Based on germination tests, 6 and 8 seeds respectively were sown per pot. All plants in a cell were harvested. 
Harvested plants in both experiments were dissected into root, stem and leaves and a section of each (as before) surface sterilised and plated on BSM. Further tissue samples from the 2006 experiment were preserved in $3 \%$ paraformaldehyde in PBST for later examination by microscopy.

\section{Statistical analysis}

Differences among treatments were analysed using a generalised linear model with a Bernouilli or binomial variance and a logit link function to estimate effects on the probability of recovering $B$. cinerea from a tissue type in a propagator cell. In 2006, all plants in a propagator cell were considered as a single sample, because seedlings were growing close together in high humidity; including the plants separately - that is, assuming infection did not spread among them - gave qualitatively similar results with hugely increased significance because of the larger sample size. The fitted model factors were back-transformed from the logit scale for presentation.

\section{RESULTS}

\section{Systemic, asymptomatic infections}

Intact plants showed no symptoms of grey mould in any experiment. B. cinerea was commonly recovered from surface-sterilised sections of healthy leaves, stems and roots of all cultivars tested, throughout the growing period (Table 1 ). Recovery of $B$. cinerea was usually least from leaves.

Distribution of infection in plants differed between seed stocks of the same cultivar in the propagator experiment (Fig 1, $P=0.03$ ) and between cultivars in the glasshouse in 2005 (Table 1, $P<0.001$ ). Infection was initially commonest in the roots, but as plants grew infection moved into stems and then leaves (Table 1 , tissue $\times$ time interaction $P<0.001$ ).

\section{Immunolabelling of $B$. cinerea in tissue sections}

Penetration of the antibodies into the tissues was poor. However, immunolabelled mycelium was seen in the interior of plants. In roots, hyphae were seen mainly in the cortex and at the interface with the vascular tissue but were not apparent within the xylem (Fig. 2, a, c). In leaves and stems hyphae were internal and again not associated with xylem (Fig. 2, e, g).

\section{Location of seedborne inoculum}

In the 2004 glasshouse experiment surface sterilisation of seed greatly reduced incidence of infection in all tissues at 2 months after sowing (Table 2; $P<0.001$ ). In 2005 glasshouse experiment the effect was smaller, differed between tissues, and changed over time, but was significant at each sampling time at $P<0.03$ or better (Table 2). At 1 month after sowing plants grown from surface-sterilised seed had no infection in stems and leaves but moderate levels in roots; the stem and leaf levels were significantly different from plants grown from the untreated seed $(P=0.03$, Table 2$)$. At 2.5 MAP 
roots and leaves had less infection in plants grown from surface sterilised seed $(P=0.003$, Table 2$)$. At 3.5 MAP leaves had less infection $(P=0.04)$ but stems and roots were unaffected by the seed surface sterilisation. The effect did not interact significantly with those of seed stock or inoculum.

\section{Applied inoculum}

In the 2004 glasshouse experiment inoculation increased infection of one cultivar, All the Year Round (interaction of inoculation and cultivar, $P=0.006$ ), but did not alter infection frequency in plants grown from other seed stocks, so that the main effect was not significant $(P=0.5$, Table 2$)$. There was no interaction with the distribution of infection among different tissues. In the 2005 glasshouse experiment inoculation increased infection in all varieties. The size of the increase interacted with time and tissue sampled $(P=0.02)$. Inoculation substantially increased the incidence of infection in stems at 2.5 MAP and throughout plants at 3.5 MAP (Table 2).

\section{Transmission of seed-borne infection to seedlings}

In the 2005 propagator experiment $B$. cinerea was recovered, before sowing, from 30/100 nonsurface-sterilised seed sampled from the stock sown (cv. Little Gem). Germination was only 40\%. At harvest, 2 MAP, incidence of B. cinerea in the roots was $25 \% \pm 12 \%(14 / 56)$ but no infection was found in stems or leaves. Soil sterilisation did not affect the infection incidence $(21 \%$ in sterilised soil and $28 \%$ in non-sterilised soil; $\mathrm{P}=0.5$ ) but seed surface sterilisation lowered seedling infection slightly (sterilised seed, 4/28; non-sterilised seed 10/28; $P=0.06$ ).

In the 2006 propagator experiment two related batches of seed of cv Tom Thumb were used. Seed bought in 2005 and kept since then at $4{ }^{\circ} \mathrm{C}$ had 0/100 infection when tested by plating on BSM after surface sterilisation, whereas seed harvested from plants grown outdoors from the first batch had $42 / 100$ infection by the same method. Establishment rates of seedlings were $39 \%$ and $20 \%$ of seed sown respectively. The two trays of the propagator had different incidences of infection but this did not interact significantly with the tissue sampled or other factors. B. cinerea was recovered from some samples of all tissues: $12 \%$ of roots, $9 \%$ of stems and $18 \%$ of leaves. On average, B. cinerea was recovered from $75 \%$ of pots sown with outdoor grown seed and $46 \%$ of pots sown with the stored seed $(P=0.03$, unweighted generalised linear model; weighted by number of plants in pot, $P<0.001)$. Seed surface sterilisation had no significant effect on infection levels $(P=0.9)$.

\section{Genotype fingerprinting of isolates}

Isolates recovered from leaves, stems and roots of individual plants of the cultivars All the Year Round and Tom Thumb in the open glasshouse in 2005 at 2.5 MAP were genotyped at 9 microsatellite loci. The isolate used to artificially infect seedlings, ES27 (haplotype coded A), was recovered from all plants, whether inoculated or not, and in the majority of cases was recovered throughout each plant (Table 3). 


\section{DISCUSSION}

This work establishes first that healthy lettuce plants without any visual symptoms may harbour live $B$. cinerea mycelium in roots, stems and leaves and, second, that as plants grow, B. cinerea infection initially in lettuce seeds or seedling lettuce spreads to newly produced tissues. Lettuce is the second host in which this systemic, symptomless progression has been demonstrated, alongside commercial hybrid Primula (Barnes \& Shaw, 2003). While this type of growth is known in many non-pathogenic fungi and pathogens - including for example Leptosphaeria maculans, Cephalosporium graminearum and smuts - it is significant to find it in a pathogen regarded as a model of a purely necrotrophic lifestyle (van Kan, 2006).

The evidence for the presence of endophytic B. cinerea throughout lettuce plants is the regular and patterned recovery of the fungus from excised healthy tissues. This recovery could not arise from accidental contamination with spores during the experimental processing, for two reasons: (a) in previous tests, cultured spores attached to inert surfaces were completely killed by the surface sterilisation (Barnes, 2002) and (b) recovery differed greatly between types of tissue and treatments (Table 1 and 2) whereas random contamination during processing should affect all material plated at the same time and by definition should not give significant differences.

The work also establishes that, as plants grow, the $B$. cinerea infection spreads to newly produced tissues. The evidence here is of several types. (a) Surface sterilisation of seed greatly reduced infection of leaves two months after sowing in the 2004 and 2005 glasshouse experiments (Table 1). (b) In the 2005 glasshouse experiment plants were inoculated at 4 weeks old. Both six and ten weeks later, all organs of inoculated plants had more infection than controls intermixed with them (in a randomised block design). Most of the sampled organs, especially leaves and roots had grown since the inoculation. (c) Six weeks after inoculation in the 2005 glasshouse experiment, the inoculating isolate, ES27, was recovered from samples of leaves, stems, and roots which had grown since inoculation, and was much the commonest isolate recovered. (d) If these isolations mostly represented localised infections by spores produced within the glasshouse, they would be most common from the most exposed tissues, leaves, whereas roots were the most regularly infected tissue in all experiments, yet the least accessible to external inoculum (Table 2, Fig. 1).

Immunolocalisation of the infection established that hyphae are present within the cortical tissues of roots and throughout stems (Fig. 2 a, c, e). The resolution achieved was insufficient to tell how the pathogen was associated with the host cells. It seems unlikely to be intra-cellular, because organisms capable of setting up intra-cellular associations (mycorrhizae, rusts, downy and powdery mildews, for example) are mostly from higher taxa very specialised for this purpose. The hyphae observed were clearly not growing along or restricted to vascular bundles in roots, unlike Leptosphaeria maculans (Sprague et al., 2007).

Seed contamination with $B$. cinerea occurs in many species. However, where it then progresses to the germinating seedling, it has usually been reported to cause a seedling blight, as for example in linseed and chickpea (Burgess et al., 1997; Harold et al., 1997), and then progress polycyclically in the developing crop. In the work reported here, seed contamination leading to systemic infection was shown very clearly in the 2004 glasshouse experiment, in which seed surface sterilisation substantially 
reduced infection of plants at 2 MAP and directly by the frequent recovery of infected plants from seed sown in the isolation propagator. However, differences in incidence in the propagator were smaller than expected from seed testing, but in the expected direction. This is consistent with seed origin of infection if plating on BSM does not detect all infections.

Inoculation with dry spores was extremely effective in the 2005 greenhouse experiments but did not have a significant effect in 2003/4. The most likely reason for this difference is higher background spore levels in autumn 2003, at the time of inoculation of the 2003/4 experiment. The density of inoculation, around 10 spores $/ \mathrm{cm}^{2}$, is very much lower than would usually be used to induce an aggressive lesion (typically $10^{3}$ spores in a droplet of a few $\mu$ l, so around $1000 \times$ higher). It is possible that differences in nutritional environment and host response produced at different densities control the nutritional and life-history strategy of $B$. cinerea. These experiments were not designed to test under what conditions Botrytis can change from an endophytic phase to an aggressive phase of growth. Stress in growth, post harvest storage, or damage by other pathogens or pests, may trigger more aggressive growth and cause symptoms (Barnes \& Shaw, 2002). The isolates responsible for the systemic infection reported here seem to be similar to those responsible for aggressive infections, because isolates from non-symptomatic plants caused normal spreading brown lesions when dropinoculated on detached leaf pieces.

Because the population is normally very varied, the recovery of the inoculating isolate from uninoculated plants in 2005 is unexpected. It is unlikely to arise from independent infections by an isolate with the same haplotype as the inoculating isolate. The infections are more likely to have been caused by the redistribution of unattached spores when the inoculated plants were re-introduced into the greenhouse, with low levels of background infection meaning that plants had few pre-existing infections. Shafia (2008) reported similar results using very sparse inoculum of marked isolates: Lettuce known to be free of infection were successfully inoculated, while pre-infected plants could not be further inoculated.

A similar near-endophytic life-history was previously confirmed in hybrid commercial $P$. x polyanthus (Barnes \& Shaw, 2003), but is somewhat at variance with detailed studies of the infection cycle of the pathogen in other hosts. Short phases of endophytic growth by Botrytis within undamaged plant tissues have been reported in strawberry (Bristow et al., 1986), blackcurrant (McNicol \& Williamson, 1989) and raspberry (Williamson et al., 1987), but these were localised and in raspberry, blackcurrant and grape followed entry through flower parts.

Many plants harbour rich endophytic floras (Crozier et al., 2006; Faeth, 2002; Gange et al., 2007; Rudgers et al., 2004). Symptomless infections by B. cinerea are widespread in roots an upper parts of several wild species, both from the Asteraceae and other families. (Gange et al., 2007; Rajaguru, 2008; Shafia, 2009; Spotts \& Serdani, 2006). In Gange et al. (2007), using non-selective media, the commonest fungi recovered were species of Cladosporium, Alternaria, Chaetomium, Gliomastix and Epicoccum. It is interesting that endophytic infections of other fungi (Acremonium spp., Plectosporium tabacinum, Fusarium spp.) have been found recently in commercial crops of lettuce, chicory, fennel and celery (D'Amico et al., 2008); it could well be that endophytic infections of $B$. cinerea in lettuces have not been found because they were not anticipated and no attempt was made to isolate the fungus from roots and stems. Our use of semi-selective medium may also have allowed us 
to recover B. cinerea in the presence of more competitive fungi. Some fungal endophytes are known to produce secondary metabolites that are beneficial to the host in that they protect the plant against root invading nematodes (Hallmann \& Sikora, 1996); others benefit plant growth or alter nutrient cycling (Lemons et al., 2005; Omacini et al., 2006), and there are widespread reports of endophytes altering insect plant interactions (Jallow et al., 2008). Although D'Amico et al. (2008) showed that cultures of most of the fungi they recovered were pathogenic when inoculated to axenically grown plants in tissue culture jars, this is not very informative about the ecological function of the fungi in nature.

B. cinerea is most studied as a necrotrophic pathogen excreting a complex of toxic compounds that can overcome plant defences in a very active way. Such active infections are generally only found when fruits ripen and pectin levels change or vegetative tissues become physically damaged. In the endophytic phase $B$. cinerea must either avoid raising plant defences by not producing toxic compounds or produce toxic compounds at some level which allows it to continue to grow in the presence of host plant responses. The last possibility could even be advantageous to the host plant, either by priming it against aggressive attack by $B$. cinerea or other pathogens, or by deterring herbivores. However, we have not yet tested such hypotheses.

To summarise, this study has established that both seed-borne and airborne infection of lettuce seedlings with $B$. cinerea give rise to long-lived systemic endophyte-like infections in all parts of plants, similar to endophytic infections found in other asteracae by other fungi (Gange et al., 2007), and the B. cinerea infections previously found in Primula xpolyantha (Barnes \& Shaw, 2003). Further work remains to be done particularly studies on vertical transmission of the fungus within the host; the frequency with which such infections occur in wild plants and other commercial crops; and the functional implications of these overlooked infections.

\section{ACKNOWLEDGEMENTS}

Some of this work was funded by a studentship from the Ghana Government to E.N.K. Sowley. S.R. Pountney assisted with the confocal microscopy.

\section{REFERENCES}

Barnes, S.E. (2002) The epidemiology of Botrytis cinerea on pot-grown ornamentals. $\mathrm{PhD}$ thesis, University of Reading, Reading, UK.

Barnes, S.E. \& Shaw, M.W. (2002) Factors affecting symptom production by latent Botrytis cinerea in Primula x polyantha. Plant Pathology, 51, 746-754.

Barnes, S.E. \& Shaw, M.W. (2003) Infection of commercial hybrid primula seeds by Botrytis cinerea and latent disease spread through the plants. Phytopathology, 93, 573-578. 
B. cinerea/lettuce MS 3-April-2009

Bristow, P.R., McNicol, R.J., \& Williamson, B. (1986) Infection of strawberry flowers by Botrytis cinerea and its relevance to grey mould development. Annals of Applied Biology, 109, 545 554.

Burgess, D., Bretag, T., \& Keane, P. (1997) Seed to seed transmission of Botrytis cinerea in chickpea and disinfection of seed with moist heat. Australian Journal of Experimental Agriculture, 37, 223-229.

Coertze, S. \& Holz, G. (2002) Epidemiology of Botrytis cinerea on grape: wound infection by dry, airborne conidia. South African Journal of Enology and Viticulture, 23, 72-77.

Crozier, J.A., Thomas, S.E., Aime, M.C., Evans, H.C., \& Holmes, K.A. (2006) Molecular characterization of fungal endophytic morphospecies isolated from stems and pods of Theobroma cacao. Plant Pathology, 55, 783-791.

D'Amico, M., Frisullo, S., \& Cirulli, M. (2008) Endophytic fungi occurring in fennel, lettuce, chicory, and celery - commercial crops in southern Italy. Mycological Research, 112, 100-107.

Edwards, S.G. \& Seddon, B. (2001) Selective media for the specific isolation and enumeration of Botrytis cinerea conidia. Letters in Applied Microbiology, 32, 63-66.

Elad, Y., Williamson, B., Tudzynski, P., \& Delen, N., eds. (2004) Botrytis: Biology, Pathology and Control. Kluwer, Dordrecht, NL.

Faeth, S.H. (2002). Are endophytic fungi defensive plant mutualists? (In, Oikos, (pp. 98 1, 25-36). Oxford: Blackwell Publishers.)

Fournier, E., Giraud, T., Loiseau, A., Vautrin, D., Estoup, A., Solignac, M., Cornuet, J.M., \& Brygoo, Y. (2002) Characterization of nine polymorphic microsatellite loci in the fungus Botrytis cinerea (Ascomycota). Molecular Ecology Notes, 2, 253-255.

Gange, A.C., Dey, S., Currie, A.F., \& Sutton, B.C. (2007) Site- and species-specific differences in endophyte occurrence in two herbaceous plants. Journal of Ecology, 95, 614-622.

Hallmann, J. \& Sikora, R.A. (1996) Toxicity of fungal endophyte secondary metabolites to plant parasitic nematodes and soil-borne plant pathogenic fungi. European Journal of Plant Pathology, 102, 155-162.

Harold, J.F.S., Fitt, B.D.L., \& Landau, S. (1997) Temperature and effects of seed-borne Botrytis cinerea or Alternaria linicola on emergence of linseed (Linum usitatissimum) seedlings. Journal of Phytopathology, 145, 89-97.

Hartley, S.E. \& Gange, A.C. (2009) Impacts of plant symbiotic fungi on insect herbivores: mutualism in a multitrophic context. Annual Review of Entomology, 54, 323-342.

Huang, H. \& Erickson, R.S. (2005) Control of lentil seedling blight caused by Botrytis cinerea using microbial seed treatments. Plant Pathology Bulletin, 14, 35-40. 
Jallow, M.F.A., Dugassa-Gobena, D., \& Vidal, S. (2008) Influence of an endophytic fungus on host plant selection by a polyphagous moth via volatile spectrum changes. Arthropod-Plant Interactions, 2, 53-62.

Keller, M., Viret, O., \& Cole, F.M. (2003) Botrytis cinerea infection in grape flowers: defense reaction, latency, and disease expression. Phytopathology, 93, 316-322.

Lemons, A., Clay, K., \& Rudgers, J.A. (2005) Connecting plant-microbial interactions above and belowground: a fungal endophyte affects decomposition. Oecologia, 145, 595-604.

McNeill, B.H. (1953) A Botrytis root rot condition in Lettuce. Plant Disease Reporter, 37, 618-619.

McNicol, R.J. \& Williamson, B. (1989) Systemic infection of black currant flowers by Botrytis cinerea and its possible involvement in premature abscission of fruits. Annals of Applied Biology, 114, 243-254.

Meyer, U. \& Dewey, F.M. (2000) Efficacy of different immunogens for raising monoclonal antibodies to Botrytis cinerea. Mycological Research, 104, 979-987.

Michailides, T.J. \& Elmer, P.A.G. (2000) Botrytis gray mold of kiwifruit caused by Botrytis cinerea in the United States and New Zealand. Plant Disease, 84, 208-223.

Omacini, M., Eggers, T., Bonkowski, M., Gange, A.C., \& Jones, T.H. (2006) Leaf endophytes affect mycorrhizal status and growth of co-infected and neighbouring plants. Functional Ecology, 20, 226-232.

Rajaguru, B.A.P. (2008) Molecular ecology of Botrytis cinerea. PhD thesis, University of Reading.

Rudgers, J.A., Koslow, J.M., \& Clay, K. (2004). Endophytic fungi alter relationships between diversity and ecosystem properties. (In, Ecology Letters, (pp. 7 1, 42-51). Oxford: Blackwell Publishing.)

Shafia, A. (2009) Latent infection of Botrytis cinerea. PhD, University of Reading, Reading.

Silow, R.A. (1933) A systemic disease of red clover caused by Botrytis anthophila Bond. Transactions of the British Mycological Society, 18, 239-248.

Spotts, R.A. \& Serdani, M. (2006) Inoculum sources of Botrytis cinerea important to pear orchards in Oregon. Plant Disease, 90, 750-754.

Sprague, S.J., Watt, M., Kirkegaard, J.A., \& Howlett, B.J. (2007) Pathways of infection of Brassica napus roots by Leptosphaeria maculans. New Phytologist, 176, 211-222.

Tintjer, T., Leuchtmann, A., \& Clay, K. (2008) Variation in horizontal and vertical transmission of the endophyte Epichloe elymi infecting the grass Elymus hystrix. New Phytologist, 179, 236-246. 
B. cinerea/lettuce MS 3-April-2009

van Kan, J.A.L. (2006) Licensed to kill: the lifestyle of a necrotrophic plant pathogen. Trends in plant science, 11, 247-253.

Williamson, B., McNicol, R.J., \& Dolan, A. (1987) The effect of inoculating flowers and developing fruits with Botrytis cinerea on post-harvest grey mould of red raspberry. Annals of Applied Biology, 111, 285-294.

Williamson, B., Tudzynsk, B., Tudzynski, P., \& van Kan, J.A.L. (2007) Botrytis cinerea: the cause of grey mould disease. Molecular Plant Pathology, 8, 561-580. 
Table 1. Percentage of glasshouse-grown lettuce tissue samples from which Botrytis. cinerea was recovered, in relation to cultivar and tissue sampled

\begin{tabular}{|c|c|c|c|c|c|c|c|c|c|c|c|}
\hline \multirow[b]{2}{*}{ Experiment } & \multirow[b]{2}{*}{ Cultivar } & \multirow[b]{2}{*}{$\mathrm{N}^{\mathrm{b}}$} & \multicolumn{3}{|c|}{$1 \mathrm{MAP}^{\mathrm{a}}$} & \multicolumn{3}{|c|}{ 2-2.5 MAP } & \multicolumn{3}{|c|}{ 3-3.5 MAP } \\
\hline & & & Root & Stem & Leaf & Root & Stem & Leaf & Root & Stem & Leaf \\
\hline \multirow[t]{4}{*}{$2004^{c}$} & All the Year Round & 16 & & & & 69 & 44 & 44 & & & \\
\hline & Tom Thumb & 16 & & & & 75 & 50 & 50 & & & \\
\hline & Little Gem & 16 & & & & 62 & 57 & 37 & & & \\
\hline & Webbs' Wonderful & 16 & & & & 82 & 56 & 56 & & & \\
\hline \multirow[t]{4}{*}{$2005^{\mathrm{d}}$} & All the Year Round & 36 & 36 & 0 & 0 & 65 & 32 & 7 & 50 & 82 & 37 \\
\hline & Tom Thumb & 36 & 42 & 0 & 0 & 48 & 63 & 9 & 59 & 83 & 52 \\
\hline & Little Gem & 36 & 36 & 14 & 6 & 100 & 87 & 11 & 52 & 45 & 7 \\
\hline & Webbs' Wonderful & 36 & 28 & 0 & 0 & 55 & 44 & 0 & 37 & 59 & 9 \\
\hline
\end{tabular}

${ }^{\mathrm{a}} \mathrm{MAP}=$ sampling time- months after planting.

${ }^{\mathrm{b}} \mathrm{N}=$ sample size per table cell

${ }^{c} 2004$ data shown for comparison with 2005; in 2004 roots, stems and leaves were not sampled at 1 and 3.5 MAP. Main effect of plant tissue type was significant at $\mathrm{P}=0.01$, but effect of cultivar and the interaction of these factors were not significant $(\mathrm{P}=0.3$ and $\mathrm{P}=0.9$ respectively), using a GLM with binomial error and logit link function

${ }^{\mathrm{d}}$ Main effect of cultivar, plant tissue type, and their interactions with time were significant at $\mathrm{P}<0.001$ using a GLM with binomial error and logit link function 
Table 2. Frequency (\%) of lettuce plant tissue samples from which Botrytis cinerea was recovered, after the tissues were surface sterilised, in relation to experimental treatments

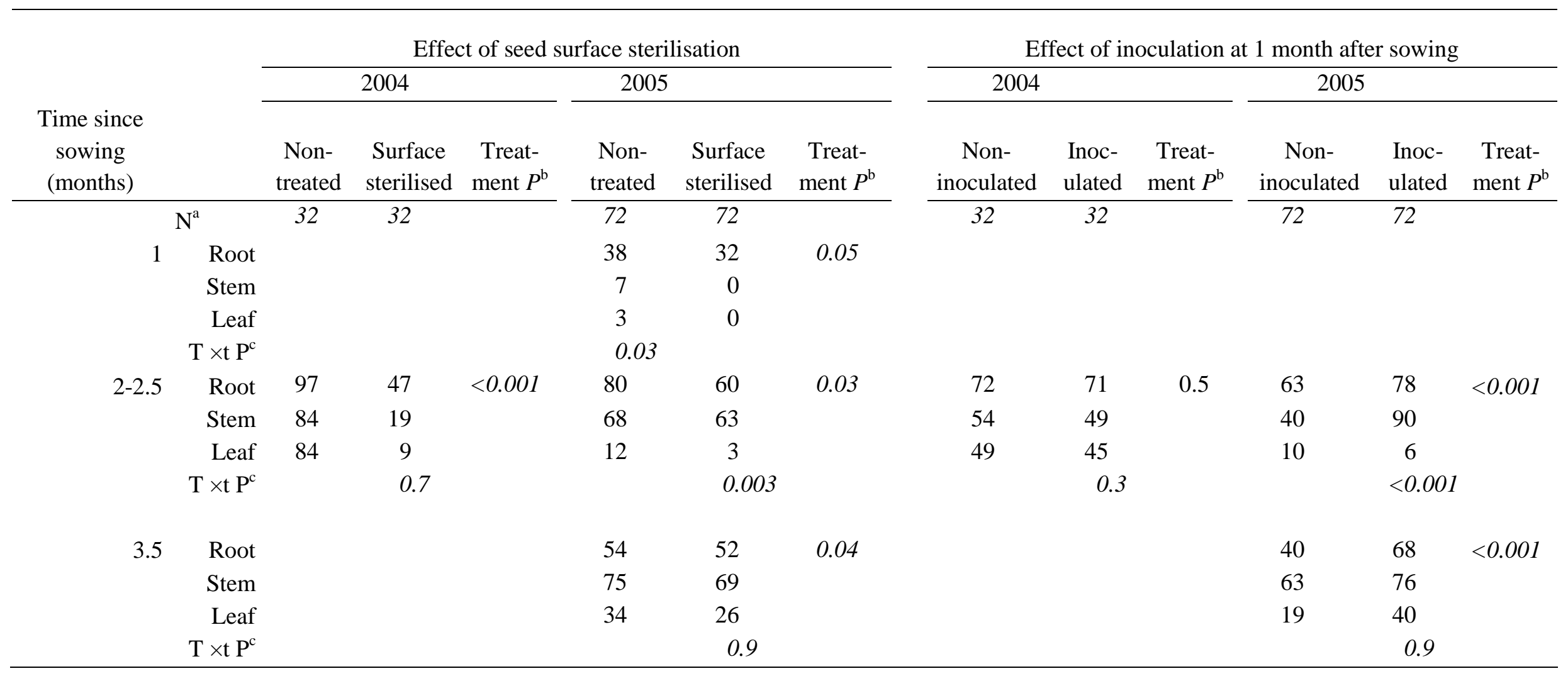

${ }^{a} \mathrm{~N}=$ Total number of plants tested at each time-point. For each treatment equal numbers of the following cultivars were tested: All Year Round, Tom Thumb, Little Gem and Webbs'Wonderful i.e. 8 of each in 2004 and 18 of each in 2005

${ }^{\mathrm{b}}$ Significance level for main effect of treatment in a generalised linear model, with effects on a logit scale and bernouilli error

${ }^{c}$ Significance level for the interaction of treatment with tissue type in a generalised linear model, with effects on a logit scale and bernouilli error 
Table 3 Haplotypes of Botrytis cinerea isolates recovered 2.5 MAP, from different tissue types in nine individual plants grown in an open glasshouse in 2005, based on DNA microsatellite fingerprints. Inoculation was 1 MAP.

\begin{tabular}{|c|c|c|c|c|c|c|c|c|c|}
\hline & \multicolumn{3}{|c|}{ Non-inoculated } & \multicolumn{6}{|c|}{ Inoculated } \\
\hline Cultivar & $\mathrm{AYR}^{\mathrm{a}}$ & $\mathrm{TT}^{\mathrm{b}}$ & TT & $\mathrm{TT}^{\mathrm{a}}$ & AYR & AYR & AYR & AYR & AYR \\
\hline Leaf & $\mathrm{A}^{\mathrm{c}}$ & A & $\mathrm{E}$ & A & A & $*^{\mathrm{d}}$ & A & A & A \\
\hline Stem & A & B & A & A & A & * & A & A & A \\
\hline Root & A & A & A & A & C & D & A & A & A \\
\hline
\end{tabular}

${ }^{a}$ cv All the Year Round

${ }^{\mathrm{b}} \mathrm{cv}$ Tom Thumb

${ }^{c}$ Code A denotes the haplotype of the inoculating isolate ES27. Each haplotype found is denoted by a different letter, $\underline{A-E}$.

${ }^{\mathrm{d}}$ no amplification detected.

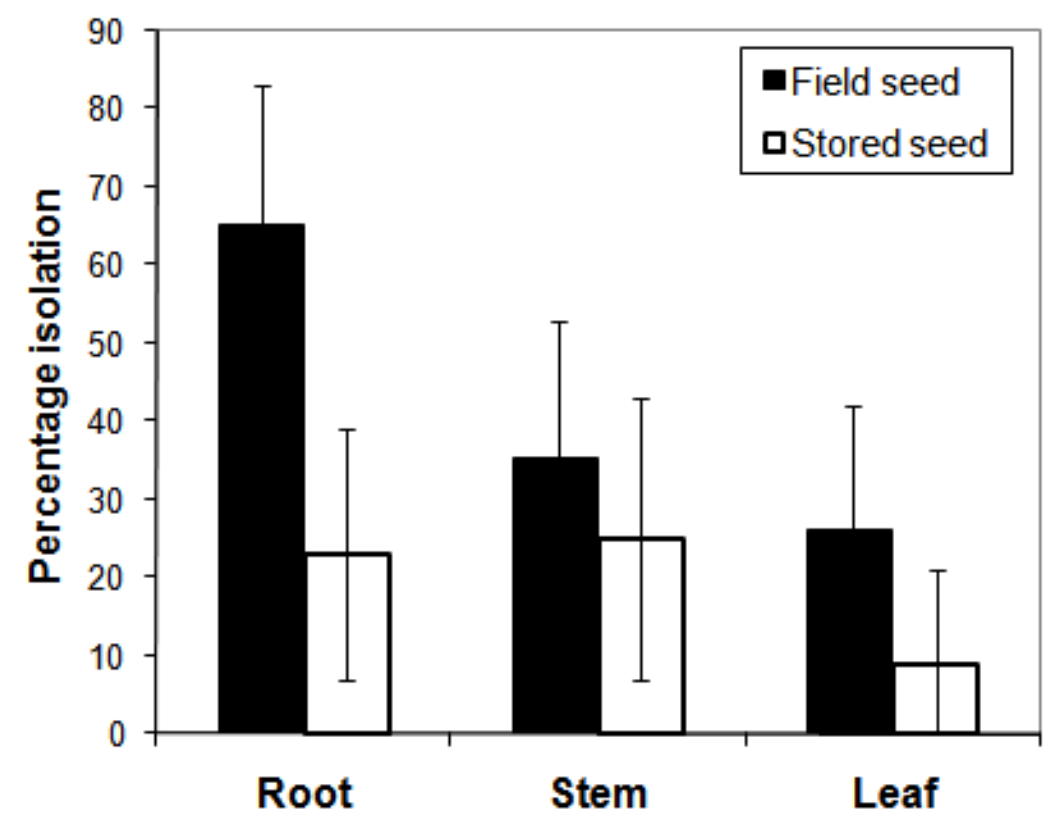

Figure 1. Incidence of B. cinerea in tissues sampled from lettuce plants cv Tom Thumb grown in a filtered, spore-free, air-flow, in relation to seed-source. Before planting, field seed had a high incidence of $B$. cinerea and stored seed, a low incidence. Error bars are 2 se derived from the generalised linear model used to analyse the data. 
B. cinerea/lettuce MS 3-April-2009

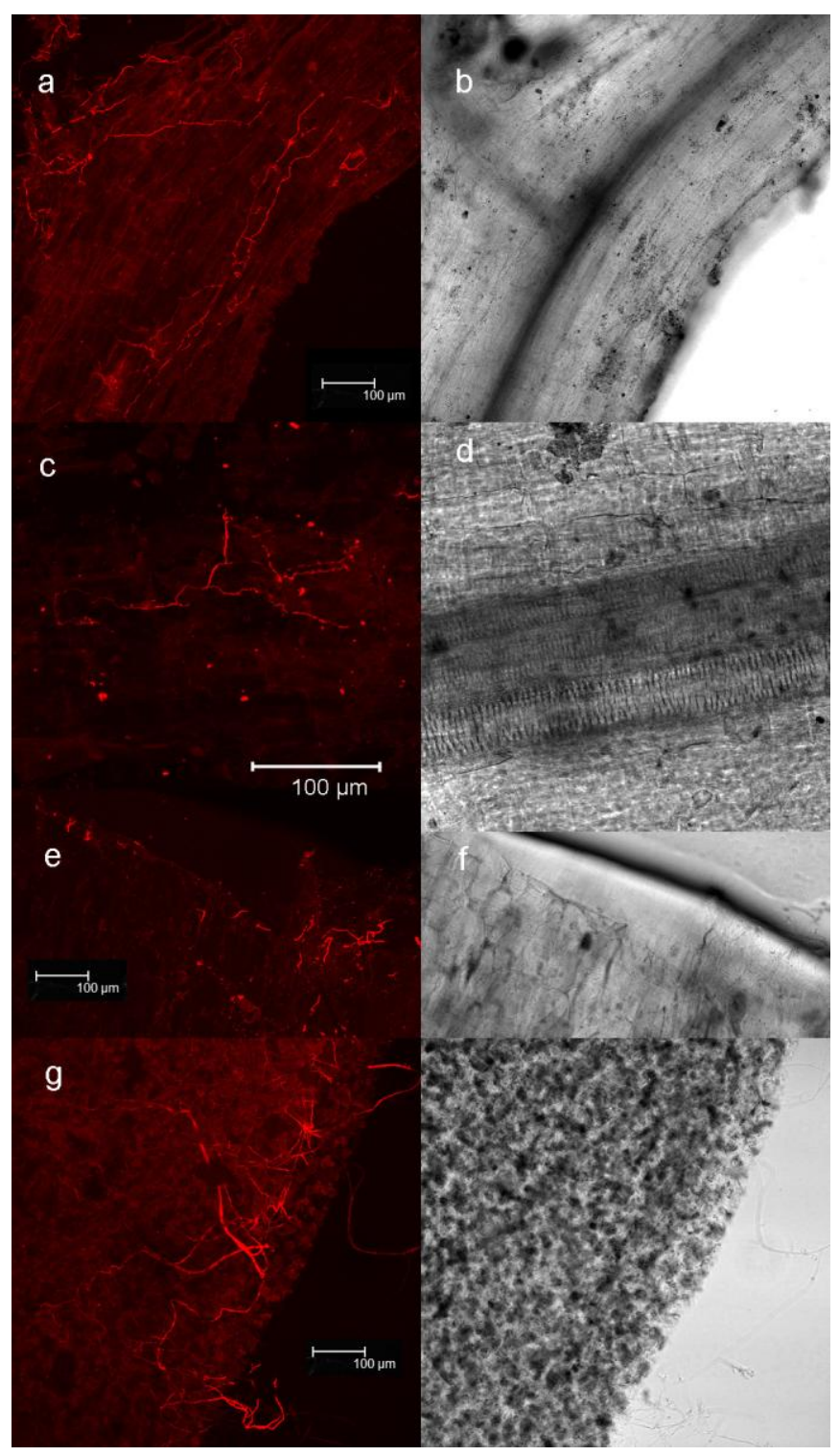

Figure 2. Visualisation of B. cinerea mycelium within squash preparations of tissues from non-symptomatic lettuce plants grown from seed in a filtered air-flow. Samples were immunolabeled with Botrytis-specific antibody BC-12.CA4 and visualised with goat anti-mouse antibody coupled to Texas Red. a-d root specimens; e,f, stem specimen; $\mathrm{g}, \mathrm{h}$, leaf disc. a,c,e,g: Composite of optical z-sections from the central one-half $\mathrm{z}$ axisof the specimen showing intensity of emission in 606-661 nm. b,d,f,h: Conventional microscopy of same area of specimens a, c, e, g respectively, to same scale. 